\title{
Development of the Children's Eating Behaviour Questionnaire
}

\author{
Jane Wardle, Carol Ann Guthrie, Saskia Sanderson, and Lorna Rapoport \\ University College London, U.K.
}

\begin{abstract}
Individual differences in several aspects of eating style have been implicated in the development of weight problems in children and adults, but there are presently no reliable and valid scales that assess a range of dimensions of eating style. This paper describes the development and preliminary validation of a parent-rated instrument to assess eight dimensions of eating style in children; the Children's Eating Behaviour Questionnaire (CEBQ). Constructs for inclusion were derived both from the existing literature on eating behaviour in children and adults, and from interviews with parents. They included reponsiveness to food, enjoyment of food, satiety responsiveness, slowness in eating, fussiness, emotional overeating, emotional undereating, and desire for drinks. A large pool of items covering each of these constructs was developed. The number of items was then successively culled through analysis of responses from three samples of families of young children $(N=131 ; N=187 ; N=218)$, to produce a 35 -item instrument with eight scales which were internally valid and had good test-retest reliability. Investigation of variations by gender and age revealed only minimal gender differences in any aspect of eating style. Satiety responsiveness and slowness in eating diminished from age 3 to 8. Enjoyment of food and food responsiveness increased over this age range. The CEBQ should provide a useful measure of eating style for research into the early precursors of obesity or eating disorders. This is especially important in relation to the growing evidence for the heritability of obesity, where good measurement of the associated behavioural phenotype will be crucial in investigating the contribution of inherited variations in eating behaviour to the process of weight gain.
\end{abstract}

Keywords: Body size, child development, eating behaviour, questionnaires, rating scales.

Abbreviations: CEBQ: Children's Eating Behaviour Questionnaire; DEBQ: Dutch Eating Behaviour Questionnaire; PCA: principal components analysis; TFEQ: Three Factor Eating Questionnaire.

\section{Introduction}

Individual differences in eating style have been hypothesised to contribute both to underweight (Marchi \& Cohen, 1990) and overweight (Barkeling, Ekman, \& Rossner, 1992). In the literature on underweight and eating disorders, there has been most emphasis on the concept of "fussy eaters", also referred to as "choosy" or "picky eaters". Most of this work has focused on children, among whom the fussy eaters can be strikingly, and sometimes capriciously, selective about what they will agree to eat. Parents identify fussy eating as problematic both because a fussy child may eat too little, and because it can be difficult to persuade them to eat a healthy diet (Harris, 1993; Rydell, Dahl, \& Sundelin, 1995). In the clinical setting, fussiness has also been implicated in failure to thrive (Wright \& Birks, 2000). Fussiness has usually been assessed clinically rather than psychometrically (Harris, 1993). We lack quantitative data showing how fussiness relates to other aspects of

Requests for reprints to: Professor Jane Wardle, Imperial Cancer Research Fund Health Behaviour Unit, Department of Epidemiology and Public Health, University College London, Gower Street, London WC1E 6BT, U.K.

(E-mail: j.wardle@ucl.ac.uk). children's eating behaviour, or whether it is linked with weight in the longer-term, but clinical observations suggest that children who are fussy eaters also tend to eat small meals, to eat slowly, and to be less interested in food (Reau, Senturio, Lebailly, \& Christoffel, 1996; Carruth et al., 1998). All of these features might be expected to be related to lower weight gain (Rydell, Dahl, \& Sundelin, 1995; Wright \& Birks, 2000). On the other hand, data from animal studies, in which rats with lesions in the ventromedial hypothalamus were used as a model for obesity, found that similar behaviour, termed finickiness, was associated with a higher risk of obesity (Schachter, 1971). The finicky animals ate less when the food was bitter tasting, but if they were offered good-tasting food, they ate more than the nonfinicky animals, i.e, they were more responsive to the palatability of their diet. Longitudinal studies, in which fussy eaters are tracked through to adulthood, will be needed if we are to resolve the longer-term outcomes associated with this eating style.

Many different eating style constructs have been implicated in the aetiology of overweight or obesity. Obese people have been hypothesised to be underresponsive to internal satiety cues, over-responsive to external food cues such as taste and smell (Schachter, 1968), to overeat in response to emotional arousal (Kaplan \& Kaplan, 1957; Slochower, 1976), and to eat too fast - thereby outpacing the onset of satiety during the course of the meal (Stunkard \& Wolff, 1956; Meyer \& 
Pudel, 1972). However, more recent studies comparing eating behaviour in obese and normal weight adults produced inconsistent results (Lowe \& Fisher, 1983; Rodin, 1981; Rodin, Schank, \& Striegel-Moore, 1989), and the concept of the "obese eating style" fell from favour. Doubts were also cast on whether any of the aspects of eating style that were observed in the obese really played a part in the development of obesity, or were in fact secondary to the obese individual's attempts to control their food intake. Deliberate control, it was argued, could keep weight below its natural level (the socalled "set-point"), and cause weight-suppressed individuals to behave as if they were food-deprived (Nisbett, 1968, 1972). Later it was suggested that even unsuccessful weight control might affect eating behaviour, since the attempts at exerting control over food intake, termed "restrained eating" (Herman \& Mack, 1975), could affect responses to food cues. An extensive body of research showed that restrained eating was associated with, and might even cause, disturbances of food intake regulation, producing lowered responsiveness to satiety cues and a greater risk of overeating (Heatherton, Polivy, \& Herman, 1989; Herman \& Polivy, 1975; Wardle \& Beales, 1988). Since that time, the concept of restrained eating has dominated psychological research into human eating behaviour, and there has been only limited interest in other aspects of eating style. In addition, as evidence has accumulated that obesity is a strongly heritable condition, the emphasis in obesity research has shifted away from psychology towards biology.

Several considerations suggest that research into individual differences in eating style might have been prematurely abandoned. First, eating styles should probably have been conceptualised as dimensional rather than categorical, with variation along any one dimension making no more than a modest contribution to variation in weight, and even then being dependent upon associated psychological and environmental factors. Second, the evidence that genetic factors are important determinants of weight should not be taken to imply that psychological factors are unimportant, but rather, that individual differences in eating style could be part of the behavioural phenotype that mediates the genetically determined effects (Faith, Johnson, \& Allison, 1997). The third consideration is that variations in eating style that are hypothesised to play a causal role in obesity might need to be assessed before obesity has developed, since once a person is obese, their eating patterns are likely to be affected by other influences as they struggle to control their weight. This points to the need for prospective studies in which eating styles are related to subsequent, rather than past, weight trajectories.

A small number of studies have investigated children's eating styles in relation to their expected future weight trajectory, by taking advantage of the well-established familial risk in obesity. Children of obese parents are at much higher risk of becoming overweight as they get older than are children of normal-weight parents (Lake, Power, \& Cole, 1997; Whitaker, Deeks, Baughcum, \& Specker, 2000). Parental weight can therefore be used as an indicator of obesity risk, providing the opportunity to investigate eating style before the anticipated weight gain has happened. One study used avidity of sucking to sweet solutions compared with plain water as an indicator of responsiveness to taste cues (Milstein, 1980), and found differences between babies with two overweight parents and babies with two normal-weight parents.
Another approach has been to assess satiety responsiveness by comparing food intake after preloads of differing energy content, reasoning that children who fail to down-regulate their intake after a larger preload are less sensitive to internal satiety signals. Children's satiety responsiveness was correlated with parental disinhibition (a combination of emotional and external eating), such that more disinhibited parents tended to have children whose appetite was less effectively "switched off" by a preload (Birch \& Sullivan, 1991). These and other studies in children typically use observations of eating behaviour as the index of eating style. Although behavioural observations are often seen as the best possible form of assessment, they can be impractical to organise, and there is always the possibility that the process of being observed may alter the children's behaviour. Parental reports of their children's eating behaviour would provide a more convenient means of data collection. Parent ratings are used in the evaluation of almost all aspects of children's behaviour, from temperament to cognitive function (Achenbach \& Edelbrook, 1983; Saudino et al., 1998), so there is reason to expect that parents might be able to report equally reliably on their children's eating behaviour. Parents are already used as informants on eating behaviour in the clinical field (Vandereycken, 1992). Paediatric studies on eating problems often depend on parental reports of aspects of food refusal, choosiness, lack of interest in food, speed of eating, and appetite (Dahl \& Sundelin, 1992; Douglas \& Bryon, 1996; Harris, 1993; Stark et al., 1995). However, there have been few attempts to develop standardised measures of children's eating behaviours. One instrument, the "Child Eating Behaviour Inventory", is a parent-rated measure of eating and mealtime problems (Archer, Rosenbaum, \& Streiner, 1991). It is principally concerned with problems such as choking and inability to use cutlery, or with parental distress about the child's eating behaviour, but it also includes a small number of eating style items concerning speed and enjoyment of eating. The total problem score has been shown to be reliable over time, and to discriminate clinical from nonclinical populations, which gives some support for the validity of parent ratings. The results are encouraging in relation to developing a broader-based instrument to assess a wider range of aspects of eating style. Braet and Van Strien (1997) have used a parent-administered version of the Dutch Eating Behaviour Questionnaire to assess external eating, emotional eating, and restrained eating in 9- to 12-year-olds. This is a useful instrument, but assesses only a limited number of aspects of eating style.

This paper reports on the development and preliminary validation of a questionnaire (the Children's Eating Behaviour Questionnaire; CEBQ) to assess eating style in young children. It covers the main dimensions of eating style that have been implicated in the development of body weight and is designed to be completed by parents in relation to their child's habitual eating behaviours.

\section{Method}

The eating style constructs to be included in the questionnaire were obtained from two sources: (1) evaluation of the existing literature on adults' and children's eating style, and (2) interviews with a sample of parents about their children's eating behaviour. Individual items were developed by modifying questions from existing (mainly adult) scales, and writing new items to reflect the eating styles which have hitherto been 
assessed in behaviour tests, or which emerged from the parental interviews.

A large initial pool of items for each construct was progressively culled following analysis of data from two samples of parents to produce an internally consistent set of scales for assessing eight aspects of eating style. The final questionnaire was administered to a third sample of parents, and the theoretically derived scale structure was confirmed by including all the items in a principal components analysis. The scale was also readministered to the same group of parents after a 2-week delay to assess the test-retest reliability of the scales. Finally, data on gender and age differences were analysed.

\section{Selection of Eating Style Constructs}

The literature on eating behaviour suggested six areas for consideration. (1) Satiety responsiveness: this is usually measured behaviourally by seeing whether food intake is reduced to compensate for a prior snack. (2) Responsiveness to food cues/external eating: this is assessed behaviourally on the basis of the amount of good-tasting versus less-good-tasting food consumed in standard conditions. Two psychometric instruments include subscales for external eating, the Three Factor Eating Questionnaire (TFEQ; Stunkard \& Messick, 1985) and the Dutch Eating Behaviour Questionnaire (DEBQ; Van Strien, Frijters, Bergers, \& Defares, 1986; Wardle, 1987), assessing it with items on self-reported desire for food following exposure to attractive food cues. (3) Emotional eating: this usually refers to eating more food during negative emotional states, although recent work has begun to distinguish emotional overeating from emotional undereating (Oliver \& Wardle, 1999; Wardle \& Gibson, 2001). Emotional overeating is measured psychometrically in the TFEQ and DEBQ by self-reported increases in appetite in a range of emotional states. (4) General interest in eating: this includes hunger, desire to eat, and enjoyment of food. These concepts are measured psychometrically with self-report questions in the TFEQ hunger scale (e.g., "I often feel so hungry, I just have to eat something"). The opposite characteristic, lack of interest in food, emerges as a common problem in the literature on children's eating problems, and the Children's Eating Behavior Inventory (Archer et al., 1991) includes several items concerned with the child's (lack of) enjoyment of food and mealtimes. (5) Speed of eating: this is usually measured behaviourally, but in the clinical literature is based on parental reports of the child dawdling or taking more than 30 minutes over a meal. (6) Food fussiness: this consists of being highly selective about the range of foods that are accepted. It emerges strongly in the literature on children's eating problems, and has been assessed using a range of ad hoc measures often based on lists of foods that might be accepted or rejected.

Interviews with 15 parents of young children (aged 2 to 6 years) from a suburban nursery school were carried out by a dietician and a psychologist to determine whether additional constructs were needed to characterise individual differences in eating style, and to confirm that the constructs identified from the experimental literature were meaningful to parents. During the interview, parents were encouraged to compare eating styles among their children if they had more than one, or to compare their child with other children, to help to draw out the differences in eating style. Parents (in practice, mothers) were very interested in discussing their children's eating behaviour and ready to note many differences between their children, e.g., "Lucy's always loved her food, but Matthew's so picky - at the moment he will only eat honey sandwiches and drink orange juice"; "William is fine as long as you don't let him have a snack, but if he even has one biscuit he can't eat his dinner".

The areas of eating style that we had identified from the literature all emerged in the parents' accounts. Fussiness was a common observation, along with slowness in eating, eating too little at meals, and being easily put off eating - all of these being aspects of undereating. Emotional eating got the least attention although most parents noted that children varied in the extent to which they were put off eating by being upset, i.e. emotional undereating was a more salient dimension than emotional overeating. Because of this, items for emotional undereating were included as well as items on emotional overeating. In addition parents mentioned social effects on eating (how the child's eating was affected by the presence of others) and distractibility (e.g., wanting to leave to play during the meal). Many parents noted that some children wanted to have drinks (usually sweetened drinks) to carry around with them. Items representing these additional constructs (responsiveness to social factors, distractibility, emotional undereating, and desire for drinks) were included in the initial questionnaire.

\section{Pilot Study}

A preliminary questionnaire was constructed that assessed the six constructs derived from the literature (food responsiveness/external eating, appetite/enjoyment of food, satiety sensitivity, slowness in eating, fussiness, and emotional overeating) and the four additional constructs that emerged from the parent interviews (emotional undereating, appetite for drinks, social eating, and distractibility). Each construct was represented by $10-16$ items. A response format of "never true", "sometimes true", and "certainly true" was chosen for the preliminary questionnaire to make it easier for parents to complete. These responses were scored 0,1 , and 2 for quantitative analyses. The questions were piloted and discussed with 20 parents, which resulted in some modification of items and wording. The full questionnaire was then handed out through 10 urban and suburban infants' schools and playgroups, whose pupils came from families from a wide variety of social backgrounds. The questionnaires were anonymous and the only additional information requested was the child's age and gender. Parents were asked to complete the questionnaire for the child who attended the nursery. Five hundred questionnaires were left with the schools, but we have no information on how many of them reached a parent. In all, 131 completed questionnaires were returned (62 girls and 69 boys) for children aged 2 to 7 years (mean age $=4.2 \pm 1.3$ ).

Data from the pilot study were used to cull the less useful items. First, items were discarded where $90 \%$ or more of the parents gave the same response. Second, principal components analysis (PCA) was used on each hypothesised scale to confirm that it had just one main factor. Items with the lowest loadings were discarded. This approach was used in preference to putting all items into one analysis at this stage, since we were aiming to develop scales based on theoretically derived constructs, rather than to use an empirical approach allowing all possible constructs to emerge. Third, alpha coefficients were calculated for the full set of items for each scale and items whose inclusion substantially reduced the alpha level were excluded.

On this basis, the items relating to social influence and mealtime distractibility were excluded as not forming coherent scales. Other scales were shortened, some items were rewritten and a few additional items were prepared. This resulted in a 57 -item version of the questionnaire containing 8 scales. The response format used for this version was modified to "never", "seldom", "sometimes", "often", and "always" (scored 0-4).

\section{Sample 2-Factor Structure and Internal Reliability}

The 57-item questionnaire was given to 320 parents from another selection of 8 urban and suburban nursery schools and nursery classes of primary schools, again with parents from a variety of social backgrounds. Overall, 187 (182 with data on age and gender) completed questionnaires were re- 
Table 1

Factor Structure and Internal Reliability (Cronbach's Alpha) from Sample $2(N=177)$ and Sample $3(N=222)$

\begin{tabular}{|c|c|c|c|c|c|c|}
\hline & \multicolumn{3}{|c|}{ Sample 2} & \multicolumn{3}{|c|}{ Sample 3} \\
\hline & $\begin{array}{c}\text { Factors } \\
\text { with } \\
\text { eigenvalue }>1\end{array}$ & $\begin{array}{c}\% \text { of variance } \\
\text { explained } \\
\text { by Factor } 1\end{array}$ & $\begin{array}{l}\text { Cronbach's } \\
\text { alpha }\end{array}$ & $\begin{array}{c}\text { Factors } \\
\text { with } \\
\text { eigenvalue }>1\end{array}$ & $\begin{array}{c}\% \text { of variance } \\
\text { explained } \\
\text { by Factor } 1\end{array}$ & $\begin{array}{l}\text { Cronbach's } \\
\text { alpha }\end{array}$ \\
\hline Food responsiveness & 1 & 56 & .80 & 1 & 59 & .82 \\
\hline Enjoyment of food & 1 & 78 & .91 & 1 & 78 & .91 \\
\hline Emotional overeating & 1 & 71 & .79 & 1 & 58 & .72 \\
\hline Desire to drink & 1 & 82 & .89 & 1 & 84 & .90 \\
\hline Satiety responsiveness & 1 & 50 & .74 & 1 & 61 & .83 \\
\hline Slowness in eating & 1 & 57 & .74 & 1 & 63 & .80 \\
\hline Emotional undereating & 1 & 58 & .74 & 1 & 58 & .75 \\
\hline Fussiness & 1 & 70 & .91 & 1 & 69 & .91 \\
\hline
\end{tabular}

turned (78 girls, 100 boys, 4 with no gender indicated). The mean age of the children was $4.2( \pm 1.4)$ years.

The same process of refining the scales was followed, with the additional aim of reducing the number of items to four to six for each of the eight scales. This resulted in a 35-item version of the questionnaire covering food responsiveness, appetite enjoyment of food, satiety responsiveness, slowness, fussiness, emotional overeating, emotional undereating, and desire for drinks.

Separate PCAs on the eight final scales showed that each of them had, as intended, a single factor with an eigenvalue greater than one, accounting for $50-80 \%$ of the variance across the eight scales. Internal reliability coefficients (Cronbach's alpha) ranged from .74 to .91 (see Table 1).

In addition, all the items were entered together into a PCA to examine the overall factor structure. This produced eight factors with eigenvalues greater than one. There was an excellent correspondence between these factors and the theoretically derived scales, with only two items loading on scales other than the ones that they had been identified with theoretically; one enjoyment item loaded onto the food responsiveness factor and one food responsiveness item loaded onto the enjoyment scale.

The 35-item version of the questionnaire was then sent to a third sample of 308 parents (Sample 3) to confirm the factor structure, assess the test-retest reliability, and examine gender and age variations in eating style. The sample was made up of 150 parents recruited from six urban nursery schools, and 158 parents who had responded to an advertisement for families to participate in research on children's eating behaviour. Of the 308 questionnaires that were sent out, 218 were returned of which 208 (111 from boys and 97 from girls) were completed for children who were 9 years or younger. The mean age of the children was $5.6( \pm 1.5)$ years.

\section{Results}

\section{Confirmation of Factor Structure}

The process of carrying out separate principal component analyses on each scale was repeated. Each of the eight scales had a single factor, each accounting for at least $58 \%$ of the variance. The results are shown in the last three columns of Table 1, and show a very similar pattern to the results from Sample 2.

All items were then entered together into a PCA to examine the overall factor structure. This produced seven factors with eigenvalues greater than one, which again matched well onto the theoretically derived scales (see Table 2). The main difference was that the items from two of the scales (satiety sensitivity and speed of eating) loaded onto the same factor. As these dimensions might usefully be separated for some purposes, they were provisionally retained as separate scales. Only one item failed to load onto the expected factor; "eating more when having nothing to do", which was part of the emotional overeating scale. In the analysis, this item loaded more highly on the food responsiveness factor, but it has been provisionally retained in the emotional overeating scale, since removing it does not materially affect the reliability of the scale and it retains the correspondence with the adult versions.

\section{Test-retest reliability}

One hundred and sixty parents $(77 \%$ of those who completed it on the first occasion) from Sample 3 repeated the questionnaire after 2 weeks. There were no differences in gender distribution, age, or any of the Time 1 eating style scores, between those who completed or didn't complete the repeat questionnaire.

Mean scores at Times 1 and 2 and test-retest reliabilities (Pearson correlations) were calculated for each scale (see Table 3). The mean differences between scores at Time 1 and Time 2 were all very small and none were significant. Test-retest reliability was high for all scales except the two emotional eating scales, which had reliabilities of .52 and .64. To test the possibility that reliability increased with age, the correlations were calculated separately for children aged 4 and under, 5, and 6 and older. However, there was no significant difference in the correlations across age groups.

\section{Correlations between Scales-Samples 2 and 3}

Correlations between the scales in Samples 2 and 3 are shown in Table 4 (Sample 2 data are below the diagonal and Sample 3 data above the diagonal) and they show very similar patterns of correlation. The results also suggest that the scales cluster in a fairly coherent way. The positive eating responsive scales (food responsiveness, enjoyment of food, desire to drink, and emotional overeating) tend to be positively intercorrelated and negatively correlated with the negative items (satiety responsiveness, slowness of eating, fussiness, and emotional overeating).

\section{Age and Gender Differences-Samples 2 and 3 Combined}

Table 5 shows the scale scores by gender and age group for the two samples combined. To examine age effects, the samples were subdivided into five approximately 
Table 2

Factor Loadings on Varimax Rotated Solution of Principal Components Analysis with All Items Included in Sample 3

\begin{tabular}{|c|c|c|c|}
\hline Scale name and items & Loading & Scale name and items & Loading \\
\hline Satiety responsiveness/Slowness in eating ${ }^{\mathrm{a}}$ & & Enjoyment of food (Factor $4 ; 7 \%$ variance) & \\
\hline (Factor $1 ; 28 \%$ variance) & & My child enjoys eating & .68 \\
\hline My child gets full up easily & .71 & My child loves food & .64 \\
\hline My child has a big appeitite & .57 & My child is interested in food & .57 \\
\hline $\begin{array}{l}\text { My child leaves food on his/her plate at the end } \\
\text { of a meal }\end{array}$ & .66 & $\begin{array}{l}\text { My child looks forward to mealtimes } \\
\text { Desire to drink (Factor } 5 ; 5 \% \text { variance) }\end{array}$ & .62 \\
\hline $\begin{array}{l}\text { My child gets full before his/her meal is finished } \\
\text { My child cannot eat a meal if } s / \text { he has had a }\end{array}$ & .72 & $\begin{array}{l}\text { If given the chance, my child would always be } \\
\text { having a drink }\end{array}$ & .89 \\
\hline $\begin{array}{l}\text { snack just before } \\
\text { My child eats slowly }\end{array}$ & $\begin{array}{l}.59 \\
.78\end{array}$ & $\begin{array}{l}\text { If given the chance, my child would drink } \\
\text { continuously throughout the day }\end{array}$ & .90 \\
\hline $\begin{array}{l}\text { My child takes more than } 30 \text { minutes to finish a } \\
\text { meal }\end{array}$ & .71 & $\begin{array}{l}\text { My child is always asking for a drink } \\
\text { Emotional undereating (Factor } 6 ; 4 \% \text { variance) }\end{array}$ & .88 \\
\hline My child finishes his/her meal very quickly & .72 & My child eats less when $\mathrm{s} /$ he is upset & .84 \\
\hline $\begin{array}{l}\text { My child eats more and more slowly during the } \\
\text { course of a meal }\end{array}$ & .77 & $\begin{array}{l}\text { My child eats less when s/he is angry } \\
\text { My child eats less when s/he is tired }\end{array}$ & $\begin{array}{l}.73 \\
.60\end{array}$ \\
\hline Fussiness (Factor 2; $13 \%$ variance) & & My child eats more when s/he is happy & .70 \\
\hline My child enjoys tasting new foods & .88 & Emotional overeating (Factor $7 ; 3 \%$ variance) & \\
\hline My child enjoys a wide variety of foods & .74 & My child eats more when anxious & .85 \\
\hline $\begin{array}{l}\text { My child is interested in tasting food s/he hasn't } \\
\text { tasted before }\end{array}$ & .84 & $\begin{array}{l}\text { My child eats more when annoyed } \\
\text { My child eats more when worried }\end{array}$ & $\begin{array}{l}.71 \\
.79\end{array}$ \\
\hline My child refuses new foods at first & .85 & My child eats more when s/he has nothing else & $.28^{\mathrm{b}}$ \\
\hline $\begin{array}{l}\text { My child decides that s/he doesn't like food, } \\
\text { even without tasting it }\end{array}$ & $\begin{array}{l}.82 \\
.82\end{array}$ & to do & \\
\hline My child is difficult to please with meals & .64 & & \\
\hline Food responsiveness (Factor 3;9\% variance) & & & \\
\hline My child's always asking for food & .65 & & \\
\hline $\begin{array}{l}\text { If given the chance, my child would always have } \\
\text { food in his/her mouth }\end{array}$ & .79 & & \\
\hline $\begin{array}{l}\text { Given the choice, my child would eat most of } \\
\text { the time }\end{array}$ & .81 & & \\
\hline If allowed to, my child would eat too much & .71 & & \\
\hline $\begin{array}{l}\text { Even if my child is full up, s/he finds room to } \\
\text { eat his/her favourite food }\end{array}$ & .56 & & \\
\hline
\end{tabular}

${ }^{\text {a }}$ Satiety, sensitivity, and slowness loaded on to the same factor in the final solution, but are maintained as separate subscales, since they may differentiate in older age groups.

${ }^{\mathrm{b}}$ Eating more when bored loaded most highly on to the externality factor (.63), but has provisionally been retained on the emotional eating factor, as a similar item appears on the emotional eating subscale of the DEBQ, so it provides better comparability.

Table 3

Means and Test-retest Reliability for Sample 3 Respondents Who Completed the Questionnaire on Both Occasions $(N=160)$ : All Scales Scored 1 (Lowest) to 5 (Highest)

\begin{tabular}{|c|c|c|c|c|c|}
\hline & \multicolumn{2}{|c|}{ Time 1} & \multicolumn{2}{|c|}{ Time 2} & \multirow{2}{*}{$\frac{\text { Correlation }}{(\mathrm{t} 1-\mathrm{t} 2)}$} \\
\hline & Mean & $(S D)$ & Mean & $(S D)$ & \\
\hline Food responsiveness & 2.2 & $(0.8)$ & 2.2 & $(0.7)$ & .83 \\
\hline Enjoyment of food & 3.6 & $(0.8)$ & 3.5 & $(0.8)$ & .87 \\
\hline Emotional overeating & 1.9 & $(0.6)$ & 1.9 & $(0.6)$ & .52 \\
\hline Desire to drink & 2.8 & (1.1) & 2.6 & $(1.1)$ & .85 \\
\hline Satiety responsiveness & 3.0 & $(0.7)$ & 3.0 & $(0.7)$ & .85 \\
\hline Slowness in eating & 3.0 & $(0.8)$ & 3.0 & $(0.8)$ & .83 \\
\hline Emotional undereating & 3.0 & $(0.8)$ & 2.7 & $(0.8)$ & .64 \\
\hline Fussiness & 3.1 & $(0.9)$ & 3.0 & $(0.8)$ & .87 \\
\hline
\end{tabular}

equal-sized age groups: children who were aged 3 years or under $(N=76), 4(N=102), 5(N=102), 6(N=68)$, and 7 and over $(N=73)$. Age effects were analysed using analysis of variance. For each variable we tested the significance of the linear term in the contrast, to determine if the means were ordered across age groups.

The only gender difference that approached significance was fussiness, which was slightly higher in boys than girls $(t=2.4, p=.02)$.
Food responsiveness showed a linear increase with age, $F(4,395)=6.8, p=.009$, as did enjoyment of food, $F(4,395)=11.1, p<.001$. Satiety responsiveness, $F(4,395)=15.4, p<.001$, and slowness, $F(4,395)=30.8$, $p<.001$, decreased with age. There was also a decrease for emotional undereating, $F(4,395)=8.9, p=.003$. Desire to drink decreased slightly, $F(4,395)=4.6, p=.03$, whereas fussiness and emotional overeating did not vary with age. 
Table 4

Correlations between the CEBQ Subscales: Values Below the Diagonal Come from Sample 2 and Those Above the Diagonal Are from Sample 3

\begin{tabular}{|c|c|c|c|c|c|c|c|c|}
\hline CEBQ scales & $\begin{array}{c}1 \\
(\mathrm{FR})\end{array}$ & $\begin{array}{c}2 \\
(\mathrm{EF})\end{array}$ & $\begin{array}{c}3 \\
(\mathrm{EO})\end{array}$ & $\begin{array}{c}4 \\
(\mathrm{DD})\end{array}$ & $\begin{array}{c}5 \\
(\mathrm{SR})\end{array}$ & $\begin{array}{c}6 \\
(\mathrm{SE})\end{array}$ & $\begin{array}{c}7 \\
(\mathrm{EU})\end{array}$ & $\begin{array}{c}8 \\
(\mathrm{FU})\end{array}$ \\
\hline 1. Food responsiveness (FR) & - & $.44^{* *}$ & $.49 * *$ & $.31 * *$ & $-.37 * *$ & $-.23 * *$ & -.05 & -.07 \\
\hline 2. Enjoyment of food (EF) & $.55 * *$ & - & $.16^{*}$ & -.05 & $-.70 * *$ & $-.59 * *$ & $-.26 * *$ & $-.53 * *$ \\
\hline 3. Emotional overeating (EO) & $.23 * *$ & .03 & - & $.14^{*}$ & -.12 & -.10 & $.21 * *$ & -.05 \\
\hline 4. Desire to drink (DD) & $.27 * *$ & -.03 & .15 & - & .10 & .13 & .09 & $.14^{*}$ \\
\hline 5. Satiety responsiveness (SR) & $-.44 * *$ & $-.61 * *$ & -.06 & .08 & - & $.67 * *$ & $.37 * *$ & $.39 * *$ \\
\hline 6. Slowness in eating (SE) & $-.30^{* *}$ & $-.47 * *$ & -.15 & .10 & $.52 * *$ & - & $.28 * *$ & $.23 * *$ \\
\hline 7. Emotional undereating (EU) & .00 & -.14 & $.26 * *$ & .11 & $.26 * *$ & .13 & - & $.13 *$ \\
\hline 8. Fussiness (FU) & $-.26^{* *}$ & $-.61 * *$ & -.04 & .07 & $.44 * *$ & $.26^{* *}$ & .09 & - \\
\hline
\end{tabular}

$* p<.01 ; * * p<.001$.

Table 5

Means (SD) of CEBQ Subscale Scores by Gender and Age-group from Samples 2 and $3(N=400)$

\begin{tabular}{|c|c|c|c|c|c|c|c|}
\hline & \multicolumn{2}{|c|}{ Gender } & \multicolumn{5}{|c|}{ Age group } \\
\hline & $\begin{array}{c}\text { Girls } \\
(N=181)\end{array}$ & $\begin{array}{c}\text { Boys } \\
(N=215)\end{array}$ & $\begin{array}{c}\text { Up to } 3 \text { years } \\
(N=76)\end{array}$ & $\begin{array}{c}4 \text { years } \\
(N=102)\end{array}$ & $\begin{array}{c}5 \text { years } \\
(N=81)\end{array}$ & $\begin{array}{l}6 \text { years } \\
(N=68)\end{array}$ & $\begin{array}{c}7 \text { years plus } \\
(N=73)\end{array}$ \\
\hline Food responsiveness & $2.2(0.8)$ & $2.3(0.8)$ & $2.2(0.8)$ & $2.1(0.7)$ & $2.3(0.7)$ & $2.4(0.8)$ & $2.4(0.9)$ \\
\hline Enjoyment of food & $3.6(0.9)$ & $3.6(0.8)$ & $3.6(0.9)$ & $3.3(0.9)$ & $3.8(0.8)$ & $3.7(0.8)$ & $3.9(0.8)$ \\
\hline Emotional overeating & $1.8(0.6)$ & $1.8(0.6)$ & $1.7(0.7)$ & $1.7(0.6)$ & $1.8(0.5)$ & $1.9(0.7)$ & $1.8(0.7)$ \\
\hline Desire to drink & $2.9(1.2)$ & $2.9(1.1)$ & $3.1(1.2)$ & $2.9(1.1)$ & $3.0(1.0)$ & $2.8(1.1)$ & $2.8(1.2)$ \\
\hline Satiety responsiveness & $3.1(0.7)$ & $3.1(0.7)$ & $3.2(0.5)$ & $3.3(0.6)$ & $3.0(0.7)$ & $2.9(0.8)$ & $3.0(0.8)$ \\
\hline Slowness in eating & $3.2(0.8)$ & $3.1(0.8)$ & $3.4(0.7)$ & $3.4(0.8)$ & $3.1(0.7)$ & $2.9(0.9)$ & $2.8(0.8)$ \\
\hline Emotional undereating & $3.0(0.7)$ & $3.1(0.8)$ & $3.3(0.8)$ & $3.1(0.8)$ & $3.0(0.6)$ & $2.9(0.7)$ & $3.0(0.8)$ \\
\hline Fussiness & $2.9(0.9)$ & $3.1(0.9)$ & $2.9(0.8)$ & $3.1(0.9)$ & $2.9(0.9)$ & $3.1(0.9)$ & $2.9(0.9)$ \\
\hline
\end{tabular}

\section{Discussion}

This paper describes the development of a multidimensional questionnaire to assess eating style in children, based on parents' reports of their child's behaviour. Individual differences in eating behaviour were conceptualised as having several dimensions, not necessarily entirely independent of one another. On the basis of the literature on eating style and obesity, several aspects of eating behaviour have been implicated, including externality, emotional eating, satiety responsiveness, and speed of eating (Kaplan \& Kaplan, 1957; Meyer \& Pudel, 1972; Schachter, 1968; Slochower, 1976; Stunkard \& Wolff, 1956). From the literature on underweight, issues of enjoyment of food, slowness, and fussiness appear to be important (Caruth et al., 1998; Douglas \& Bryon, 1996; Harris, 1993; Marchi \& Cohen, 1990; Reau, Senturia, Lebailly, \& Christoffel, 1996; Rydell, Dahl, \& Sundelin, 1995). In the first stage of this work, openended interviews with parents were used to determine which aspects of individual differences in eating style they were able to identify in their children. This work confirmed that all the dimensions that had been identified in the experimental literature appeared in the parents' accounts, along with two other constructs, emotional undereating and a constant need for drinks. Emotional undereating represents in some ways a biologically natural response to stress since most states of emotional arousal reduce gut activity (Wardle \& Gibson, 2001). To parents, however, getting upset during a meal was just another factor that tended to put some children off their food, and so we included it in the final scale. The issue of some children wanting to have a drink with them all the time is something that has recently attracted attention in the health literature. Higher consumption of soft drinks has been found to be associated with higher total energy intake (Harnack, Stang, \& Story, 1999), suggesting that children who frequently drink soft drinks may be at higher risk of developing obesity.

The psychometric results suggested that the theoretically based scales of the CEBQ effectively captured the dimensions of individual differences in eating behaviour that parents could identify in their children. The scales were developed as measures of constructs from the literature on eating behaviour, but more or less the same scale structure emerged statistically from analyses of the pattern of intercorrelations between items in the whole item pool (PCA). The main exception was that satiety responsiveness and speed of eating loaded onto the same scale. However, this accords with what is known about the development of satiety over the course of a meal, which can be shown to be reflected in a negative acceleration of intake rate over the meal (Meyer \& Pudel, 1972).

The data from the two samples were used to examine gender and age differences in eating style among the participants in two of the samples. There were few gender differences, except that boys had higher levels of fussiness about eating. This is interesting because by the teenage years there are usually strong gender differences in eating style, often attributed to girls' concern about their weight leading to dietary restraint and thereby a different emotional relationship with food and eating (Wardle, Marsland, Sheikh, Quinn, \& Federoff, 1992). It would be valuable to track the developmental trajectory of gender differences across the early years up to the point that girls and boys differentiate in their attitudes to body shape.

Even in the restricted range of ages of these samples, there were age differences in eating style. As children got older, parents were less likely to see them as easily-sated, slow eaters and more likely to see them as being responsive to food cues and enjoying food. This may 
reflect genuine developmental shifts in eating style or an interaction with changes in parental control over food, whereby children have more chance to choose what they eat as they get older. Again, a systematic investigation of the development of eating style, possibly in association with parental behaviours, would be useful.

One reason for developing the CEBQ was to make it easier to investigate the contribution of individual differences in eating style to the development of obesity. There are sporadic observations which suggest that external eating, emotional overeating, and possibly food fussiness, might be associated with the risk of obesity. Questionnaires such as the CEBQ should make it more feasible to carry out large-scale studies to investigate associations between eating style and the later development of obesity. It is also possible that eating style differences form part of the behavioural pathway through which obesity risk is passed on. If so, measurement of eating style provides one means of "putting the behaviour into behaviour genetics of obesity" (Faith, Johnson, \& Allison, 1997). We are currently evaluating the role of eating style in the development of obesity in a large sample of children from obese and nonobese families (Wardle et al., 2001). The children have been selected from a large and representative twin sample so that future analyses can test the hypothesis that the phenotypic associations established in the present study are mediated genetically. In addition, the twin sample is being followed up longitudinally so that eventually it will be possible to add the power of longitudinal analyses to help sort out cause and effect in the development of obesity.

There are a number of limitations to this study. The scales were developed through piloting with samples of families recruited from nursery classes and from respondents to an invitation to participate in research on children's eating behaviour. The response rates were comparatively low $(55-70 \%)$, and it is likely that more questionnaires were returned by families with higher levels of education, and probably also with a greater interest in issues of eating and nutrition. This could mean that some of the items might be slightly less relevant to families with less education or less interest in nutrition. Finally, the scales were shown to have good internal consistency and reasonable reliability, but further research is needed to establish their predictive value.

Acknowledgements-This work was supported by a grant from the Biotechnology and Biological Sciences Research Council.

\section{References}

Achenbach, T. M., \& Edelbrock, C. (1983). In T. M. Achenbach (Ed.), Manual for Child Behavior Checklist and Revised Child Behaviour Profile. Burlington, VT: University of Vermont.

Archer, L. A., Rosenbaum, P. L., \& Streiner, D. L. (1991). The Children's Eating Behavior Inventory: Reliability and validity results. Journal of Pediatric Psychology, 16, 629-642.

Barkeling, B., Ekman, S., \& Rossner, S. (1992). Eating behaviour in obese and normal weight 11-year-old children. International Journal of Obesity and Related Metabolic Disorders, 16, 355-360.

Berkowitz, R. I. (1983). Physical activity, eating style, and obesity in children: A review. Behavioral Medicine Update, 5 , 9-14.

Birch, L. L., \& Sullivan, S. A. (1991). Measuring children's food preferences. Journal of School Health, 61, 212-214.
Braet, C., \& Van Strien, T. (1997). Assessment of emotional, externally induced and restrained eating behaviour in nine to twelve-year-old obese and non-obese children. Behaviour Research and Therapy, 35, 863-873.

Carruth, B. R., Skinner, J., Houck, K., Moran, J. III, Coletta, F., \& Ott, D. (1998). The phenomenon of "picky eater": A behavioral marker in eating patterns of toddlers. Journal of the American College of Nutrition, 17, 180-186.

Dahl, M., \& Sundelin, C. (1992). Feeding problems in an affluent society. Follow-up at four years of age in children with early refusal to eat. Acta Paediatrica, 81, 575-579.

Douglas, J. E., \& Bryon, M. (1996). Interview data on severe behavioural eating difficulties in young children. Archives of Disease in Childhood, 75, 304-308.

Faith, M. S., Johnson, S. L., \& Allison, D. B. (1997). Putting the behavior into the behavior genetics of obesity. Behavior Genetics, 27, 423-439.

Harnack, L., Stang, J., \& Story, M. (1999). Soft drink consumption among US children and adolescents: Nutritional consequences. Journal of the American Dietetic Association, 99, 436-441.

Harris, G. (1993). Feeding problems and their treatment. In S. T. James, I. Roberts, \& G. Harris (Eds.), Infant crying, feeding and sleeping: Development, problems and treatments. The developing body and mind (pp. 118-132). London: Harvester Wheatsheaf.

Heatherton, T. F., Polivy, J., \& Herman, C. P. (1989). Restraint and internal responsiveness: Effects of placebo manipulations of hunger state on eating. Journal of Abnormal Psychology, 98, 89-92.

Herman, C. P., \& Mack, D. (1975). Restrained and unrestrained eating. Journal of Personality, 43, 647-660.

Herman, C. P., \& Polivy, J. (1975). Anxiety, restraint, and eating behavior. Journal of Abnormal Psychology, 84, 66-72.

Kaplan, H. I., \& Kaplan, H. S. (1957). The psychosomatic concept of obesity. Journal of Nervous and Mental Disease, $125,181-201$.

Lake, J. K., Power, C., \& Cole, T. J. (1997). Child to adult body mass index in the 1958 British birth cohort: Associations with parental obesity. Archives of Disease in Childhood, 77, 376-381.

Lowe, M. R., \& Fisher, E. B. Jr (1983). Emotional reactivity, emotional eating, and obesity: A naturalistic study. Journal of Behavioral Medicine, 6, 135-149.

Marchi, M., \& Cohen, P. (1990). Early childhood eating behaviors and adolescent eating disorders. Journal of the American Academy of Child and Adolescent Psychiatry, 29, $112-117$.

Meyer, J. E., \& Pudel, V. (1972). Experimental studies on foodintake in obese and normal weight subjects. Journal of Psychosomatic Research, 16, 305-308.

Milstein, R. M. (1980). Responsiveness in newborn infants of overweight and normal weight parents. Appetite, 1, 65-74.

Nisbett, R. E. (1968). Taste, deprivation, and weight determinants of eating behavior. Journal of Personality and Social Psychology, 10, 107-116.

Nisbett, R. E. (1972). Hunger, obesity, and the ventromedial hypothalamus. Psychological Review, 79, 433-453.

Oliver, G., \& Wardle, J. (1999). Perceived effects of stress on food choice. Physiology and Behavior, 66, 511-515.

Reau, N. R., Senturia, Y. D., Lebailly, S. A., \& Christoffel, K. K. (1996). Infant and toddler feeding patterns and problems: Normative data and a new direction. Pediatric Practice Research Group. Journal of Developmental and Behavioral Pediatrics, 17, 149-153.

Rodin, J. (1981). Current status of the internal-external hypothesis for obesity: What went wrong? American Psychologist, 36, 361-372.

Rodin, J., Schank, D., \& Striegel-Moore, R. (1989). Psychological features of obesity. Medical Clinics of North America, $73,47-66$ 
Rydell, A. M., Dahl, M., \& Sundelin, C. (1995). Characteristics of school children who are choosy eaters. Journal of General Psychology, 156, 217-229.

Saudino, K. J., Dale, P. S., Oliver, B., Petrill, S. A., Richardson, V., Rutter, M., Simonoff, E., Stevenson, J., \& Plomin, R. (1998). The validity of parent-based assessment of the cognitive abilities of 2-year olds. British Journal of Developmental Psychology, 16, 249-363.

Schachter, S. (1968). Obesity and eating. Internal and external cues differentially affect the eating behavior of obese and normal subjects. Science, 161, 751-756.

Schachter, S. (1971). Some extraordinary facts about obese humans and rats. American Psychologist, 26, 129-144.

Slochower, J. (1976). Emotional labeling and overeating in obese and normal weight individuals. Psychosomatic Medicine, 38, 131-139.

Stark, L. J., Jelalian, E., Mulvihill, M. M., Powers, S. W. Bowen, A. M., Spieth, L. E., Keating, K., Evans, S. Creveling, S., \& Harwood, I. (1995). Eating in preschool children with cystic fibrosis and healthy peers: Behavioral analysis. Pediatrics, 95, 210-215.

Stunkard, A., Coll, M., Lundquist, S., \& Meyers, A. (1980). Obesity and eating style. Archives of General Psychiatry, 37, 1127-1129.

Stunkard, A. J., \& Messick, S. (1985). The Three-Factor Eating Questionnaire to measure dietary restraint, disinhibition and hunger. Journal of Psychosomatic Research, 29, 71-83.

Stunkard, A. J., \& Wolff, H. G. (1956). A mechanism of satiety: Function and disorder in human obesity. Psychosomatic Medicine, 18, 515.

Vandereycken, W. (1992). Validity and reliability of the Anorectic Behavior Observation Scale for parents. Acta Psychiatrica Scandinavica, 85, 163-166.
Van Strien, T., Frijters, J. E. R., Bergers, G. P. A., \& Defares, P. B. (1986). Dutch Eating Behaviour Questionnaire for assessment of restrained, emotional and external eating behaviour. International Journal of Eating Disorders, 5, 295-315.

Wardle, J. (1987). Eating style: A validation study of the Dutch Eating Behaviour Questionnaire in normal subjects and women with eating disorders. Journal of Psychosomatic Research, 31, 161-169.

Wardle, J., \& Beales, S. (1988). Control and loss of control over eating: An experimental investigation. Journal of Abnormal Psychology, 97, 35-40.

Wardle, J., \& Gibson, E. L. (2001). Impact of stress on diet: Processes and implications. In S. Stansfield \& M. G. Marmot (Eds.), Stress and heart disease. London: British Medical Journal Books.

Wardle, J., Marsland, L., Sheikh, Y., Quinn, M., \& Federoff, I. (1992). Eating style and eating behaviour in adolescents. Appetite, 18, 167-183.

Wardle, J., Guthrie, C. A. , Sanderson, S., Birch, L., \& Plomin, R . (2001). Food and activity preferences in children of lean and obese parents. International Journal of Obesity and Related Metabolic Disorders, 25, 971-977.

Whitaker, R. C., Deeks, C. M., Baughcum, A. E., \& Specker, B. L. (2000). The relationship of childhood adiposity to parent body mass index and eating behavior. Obesity Research, 8, 234-240.

Wright, C., \& Birks, E. (2000). Risk factors for failure to thrive: A population-based survey. Child Care, Health and Development, 26, 5-16.

Manuscript accepted 22 May 2001 